\title{
Polymerization of (o-Alkylphenyl)acetylenes and Polymer Properties
}

\author{
Yoshiharu Abe, Hiroaki Kouzai, Tomohiro Mizumoto, Toshio Masuda, ${ }^{*}$ \\ and Toshinobu Higashimura*
}

Department of Polymer Chemistry, Kyoto University, Kyoto 606-01, Japan

(Received August 25, 1993)

\begin{abstract}
Alkylphenyl)acetylenes (alkyl: Et, $n$ - $\mathrm{Bu}, n-\mathrm{C}_{6} \mathrm{H}_{13}, n-\mathrm{C}_{8} \mathrm{H}_{17}$, and iso-Pr) polymerized in high yields with $\mathrm{W}$ and $\mathrm{Mo}$ catalysts. $\mathrm{MoCl}_{5}$-based catalysts, which are not very active to phenylacetylene (PA), exhibited high activity like the $\mathrm{WCl}_{6}$ counterparts. The weight-average molecular weights $\left(\bar{M}_{w}\right)$ of the polymers having $o$ - $n$-alkyl groups were in the range $2 \times 10^{4}-55 \times 10^{4}$, being similar to or slightly higher than those of poly(PA), while the highest $\bar{M}_{w}$ value of poly $\left(o\right.$-iso-Pr-phenylacetylene) $[$ poly $($ iso-PrPA $)]$ reached $1 \times 10^{6}$. The formed polymers were dark red, and had the structure $\left[\mathrm{CH}=\mathrm{C}\left(\mathrm{C}_{6} \mathrm{H}_{4} \text {-alkyl }\right)\right]_{n}$. They were thermally more stable than poly(PA) according to the thermogravimetric analysis. The polymers with long $o-n$-alkyl groups were soluble in aliphatic solvents (e.g., hexane) unlike poly(PA), and their softening points were lower. Poly(o-iso-PrPA) was film-forming, and fairly gas-permeable $\left(P_{\mathrm{O}_{2}} 27\right.$ barrers, $P_{\mathrm{O}_{2}} / P_{\mathrm{N}_{2}}$ 2.2).

KEY WORDS Substituted Acetylene / (o-Alkylphenyl)acetylene / TransitionMetal Catalyst / Metathesis Polymerization / Substituted Polyacetylene / Gas Permeability /
\end{abstract}

In the polymerization of monosubstituted acetylenes by $\mathrm{W}$ and Mo catalysts, a general tendency has been observed that monomers with bulky substituents provide high molecular weight polymers. For instance, 1-hexyne, which is sterically not crowded, forms only oligomers whose weight-average molecular weights $\left(\bar{M}_{w}\right)$ are a few thousand. ${ }^{1,2}$ In contrast, tertbutylacetylene, which is very crowded, produces a polymer whose $\bar{M}_{w}$ exceeds $1 \times 10^{5} .^{1-4}$ The steric effect of phenylacetylene is moderate, and the $\bar{M}_{w}$ of the polymer formed is usually $2 \times 10^{4}-3 \times 10^{4} .^{1,5}$

Thus it is interesting to examine how high the molecular weight of the polymer becomes when a substituent is introduced onto the ortho position of phenylacetylene to increase steric crowding. In fact, we studied the polymerization of (o-methylphenyl)acetylene (o-MePA) to find the formation of a polymer having high molecular weight $\left(\bar{M}_{w}\right.$ up to $8 \times 10^{5}$ with
$\mathrm{W}(\mathrm{CO})_{6}-h v$ catalyst) and good thermal stability. ${ }^{6}$ It has recently been found that phenylacetylenes with even bulkier ortho groups (e.g., $\mathrm{CF}_{3}{ }^{7}$ and $\left.\mathrm{Me}_{3} \mathrm{Si}^{8,9}\right)$ yield polymers with very high molecular weight $\left(\bar{M}_{w} 1 \times 10^{6}\right.$ and above $)$.

The present study deals with the polymerization of (o-alkylphenyl)acetylenes, namely, phenylacetylenes having ethyl, $n$-butyl, $n$-hexyl, $n$-octyl, and iso-propyl groups at the ortho position ( $o$-EtPA, $o-n$-BuPA, $o-n-\mathrm{C}_{6} \mathrm{H}_{13} \mathrm{PA}$, $o-n-\mathrm{C}_{8} \mathrm{H}_{17} \mathrm{PA}$, and $o$-iso-PrPA, respectively) [eq 1]. The structure and properties of the product polymers have also been investigated.

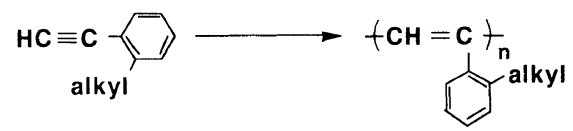

\section{EXPERIMENTAL}

Three monomers having $o-n-\mathrm{Bu}, o-n-\mathrm{C}_{6} \mathrm{H}_{13}$, and $o-n-\mathrm{C}_{8} \mathrm{H}_{17}$ groups were prepared from

\footnotetext{
* To whom correspondence should be addressed.
} 
phenylacetylene by modifying the literature method [eq 2]. ${ }^{10}$ The preparation of $o-n$ $\mathrm{C}_{6} \mathrm{H}_{13} \mathrm{PA}$ is detailed below.

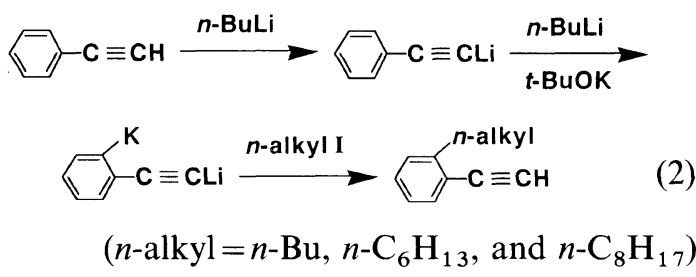

$o-\mathrm{C}_{6} \mathrm{H}_{13} \mathrm{PA}$ : After flushed with dry nitrogen, a 1-liter round-bottomed flask was equipped with a dropping funnel, a three-way stopcock, and a magnetic stirring bar. A hexane solution of $n$-BuLi ( $250 \mathrm{ml}, 0.40 \mathrm{~mol})$ was placed in the flask, and a part of hexane $(c a .130 \mathrm{ml})$ was evaporated with an aspirator. Tetrahydrofuran (THF; $130 \mathrm{ml}$; dried over sodium) was added dropwise at $-20^{\circ} \mathrm{C}$. Then, a solution of phenylacetylene $(22 \mathrm{ml}, 0.20 \mathrm{~mol})$ in THF $(50 \mathrm{ml})$ was gradually added and the reaction mixture was left for $1 \mathrm{~h}$ at $0^{\circ} \mathrm{C}$. After the mixture was cooled at $-65^{\circ} \mathrm{C}$, a solution of $\mathrm{KO}-t$-Bu $(22.5 \mathrm{~g}, 0.20 \mathrm{~mol})$ in THF (200 ml) was added dropwise followed by stirring at $-10^{\circ} \mathrm{C}$ for $2 \mathrm{~h}$. At $-65^{\circ} \mathrm{C} n-\mathrm{C}_{6} \mathrm{H}_{13} \mathrm{I}(30 \mathrm{ml}, 0.20 \mathrm{~mol})$ was added dropwise, and the mixture was left at room temperature overnight. Water $(20 \mathrm{ml})$ was carefully added. The reaction product was extracted with hexane, washed with $5 \%$ hydrochloric acid and water. The organic phase was dried over anhydrous sodium sulfate overnight. Hexane was evaporated, and the product was distilled twice from calcium hydride at reduced pressure; bp $95^{\circ} \mathrm{C} / 7 \mathrm{mmHg}$, purity $>99 \%$ (by gas chromatography (GC)).

The phenylacetylenes with $o-n-\mathrm{Bu}$ and $o-n-\mathrm{C}_{8} \mathrm{H}_{17}$ were prepared in the same way ( $n$-BuPA bp $83^{\circ} \mathrm{C} / 10 \mathrm{mmHg}, n-\mathrm{C}_{8} \mathrm{H}_{17} \mathrm{PA}$ bp $123^{\circ} \mathrm{C} / 4 \mathrm{mmHg}$ ). However, both $o$-EtPA (bp $61^{\circ} \mathrm{C} / 12.5 \mathrm{mmHg}$ ), which is difficult to perfectly separate from phenylacetylene by simple distillation, and $o$-iso-PrPA (bp $54^{\circ} \mathrm{C} / 10$ $\mathrm{mmHg}$ ), for which the foregoing process is not applicable because of difficulty in the alkylation reaction, were prepared from 2-methyl-3- butyn-2-ol and 1-alkyl-2-iodobenzenes by the same method as for (o-methylphenyl)acetylene. $^{6}$

Transition-metal chlorides and organometallic cocatalysts were commercially obtained, and used without further purification. Toluene, $\mathrm{CCl}_{4}$ etc. as polymerization solvents were washed by the standard methods, and distilled twice from calcium hydride.

Polymerizations were carried out under dry nitrogen in the same manner as described elsewhere. ${ }^{6,8,9}$ Unless otherwise stated, polymerizations were carried out in toluene (for $\mathrm{MCl}_{x}$ catalysts) or in $\mathrm{CCl}_{4}$ [for $\mathrm{M}(\mathrm{CO})_{6}-h v$ catalysts $]$ at $30^{\circ} \mathrm{C}$ for $24 \mathrm{~h} ;[\mathrm{M}]_{0}=1.0 \mathrm{M}$, $[\mathrm{Cat}]=20 \mathrm{mM}\left(\mathrm{MCl}_{x}\right.$ catalysts $)$ or $10 \mathrm{mM}$ $\left[\mathrm{M}(\mathrm{CO})_{6}-h v\right.$ catalysts $]$.

The number- and weight-average molecular weights $\left(\bar{M}_{n}\right.$ and $\bar{M}_{w}$, respectively) of polymers were determined by gel permeation chromatography (GPC) with use of a polystyrene calibration. Thermogravimetric analyses (TGA) were carried out in air with a Shimadzu 20B thermal analyzer (heating rate $10^{\circ} \mathrm{C} / \mathrm{min}$ ). IR spectra were recorded in $\mathrm{KBr}$ pellets on a Shimadzu IR435 spectrophotometer. ${ }^{13} \mathrm{C}$ NMR spectra were obtained with a JEOL FX90Q spectrometer (in $\mathrm{CDCl}_{3}$ ). Electrical conductivities were measured by the DC steady-state method at $25^{\circ} \mathrm{C}$ in the dark.

\section{RESULTS AND DISCUSSION}

\section{Polymerization of o-n-Alkylphenylacetylenes}

Table I shows results for the polymerization of $o-n-\mathrm{C}_{6} \mathrm{H}_{13} \mathrm{PA}$ by various $\mathrm{W}$ and $\mathrm{Mo}$ catalysts. The three $\mathrm{W}$ catalysts in Table I provide methanol-insoluble polymers in high yields over $75 \%$. The polymerization rate decreased in the order of $\mathrm{WCl}_{6}-\mathrm{Ph}_{4} \mathrm{Sn}>$ $\mathrm{WCl}_{6}>\mathrm{W}(\mathrm{CO})_{6}-h v$. The $\bar{M}_{w}$ values of the polymers are about $6 \times 10^{4}-1 \times 10^{5}$, and the highest value of $1 \times 10^{5}$ was attained with the $\mathrm{W}(\mathrm{CO})_{6}-h v$ catalysts.

$\mathrm{MoCl}_{5}$-based catalysts also formed poly $(o$ $n-\mathrm{C}_{6} \mathrm{H}_{13} \mathrm{PA}$ )s in good yields (Table I), whereas 
the $\mathrm{Mo}(\mathrm{CO})_{6}-h v$ catalysts was hardly effective. The $\bar{M}_{w}$ values of the polymers obtained with Mo catalysts were similar to those with $\mathrm{W}$ catalysts. These findings are quite interesting when it is taken into account that phenylacetylene does not polymerize in high yield with

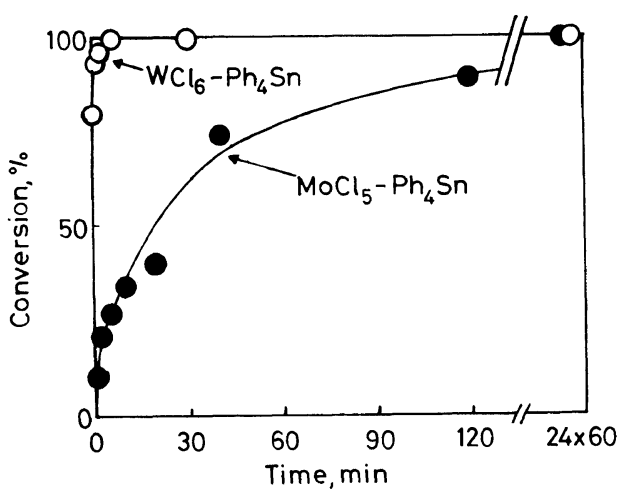

Figure 1. Time profile of the polymerization of $o-n$ $\mathrm{C}_{6} \mathrm{H}_{13} \mathrm{PA}$ (in toluene, $30^{\circ} \mathrm{C}, 24 \mathrm{~h},[\mathrm{M}]_{0}=0.50 \mathrm{M}$, [Cat $]=$ $\left.\left[\mathrm{Ph}_{4} \mathrm{Sn}\right]=10 \mathrm{mM}\right)$.
$\mathrm{MoCl}_{5}$ and the $\bar{M}_{w}$ of the polymer is no more than several thousand. ${ }^{1,5}$

As seen in Figure 1, the polymerization of $o-n-\mathrm{C}_{6} \mathrm{H}_{13} \mathrm{PA}$ by $\mathrm{WCl}_{6}-\mathrm{Ph}_{4} \mathrm{Sn}$ is completed in

Table I. Polymerization of $o-n-\mathrm{C}_{6} \mathrm{H}_{13} \mathrm{PA}$ by W and Mo catalysts ${ }^{\mathbf{a}}$

\begin{tabular}{lcrcc}
\hline \multirow{2}{*}{ Catalyst } & $\begin{array}{c}\text { Monomer } \\
\text { convn } / \%\end{array}$ & \multicolumn{3}{c}{ Polymer $^{\mathrm{b}}$} \\
\cline { 3 - 5 } & & Yield $/ \%$ & $\bar{M}_{w} / 10^{3 \mathrm{c}}$ & $\bar{M}_{n} / 10^{3 \mathrm{c}}$ \\
\hline $\mathrm{WCl}_{6}$ & 100 & 83 & 58 & 24 \\
$\mathrm{WCl}_{6}-\mathrm{Ph}_{4} \mathrm{Sn}$ & 100 & 89 & 63 & 24 \\
$\mathrm{~W}(\mathrm{CO})_{6}-h v^{\mathrm{d}}$ & 100 & 77 & 100 & 42 \\
$\mathrm{MoCl}_{5}$ & 100 & 100 & 37 & 16 \\
$\mathrm{MoCl}_{5}-\mathrm{Ph}_{4} \mathrm{Sn}$ & 98 & 98 & 120 & 30 \\
$\mathrm{Mo}(\mathrm{CO})_{6}-h v^{\mathrm{d}}$ & 23 & 2 & - & - \\
\hline
\end{tabular}

a Polymerized in toluene at $30^{\circ} \mathrm{C}$ for $24 \mathrm{~h}$; $[\mathrm{M}]_{\mathrm{o}}=$ $0.50 \mathrm{M},[\mathrm{Cat}]=\left[\mathrm{Ph}_{4} \mathrm{Sn}\right]=20 \mathrm{mM}$.

b Methanol-insoluble product.

c Determined by GPC.

d Polymerized in $\mathrm{CCl}_{4}$; [Cat $]=10 \mathrm{mM}$. (a)

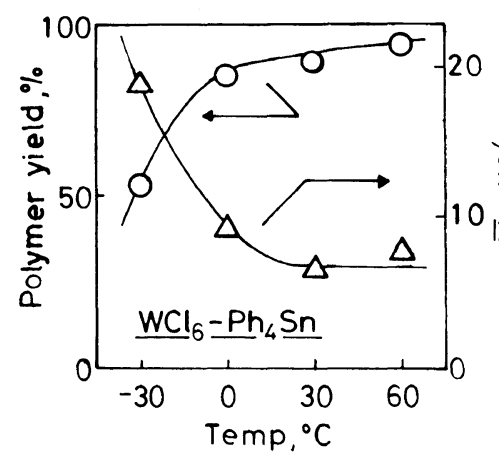

(c)

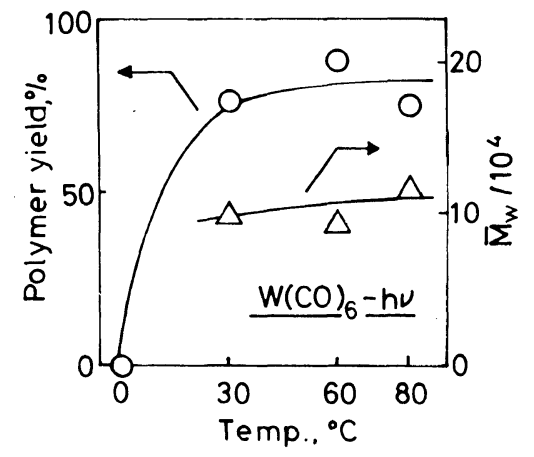

(b)

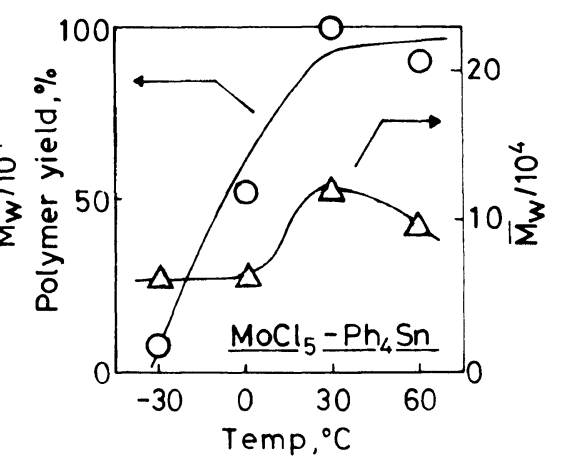

Figure 2. Effect of temperature on the polymerization of $o-n-\mathrm{C}_{6} \mathrm{H}_{13} \mathrm{PA}\left(\mathrm{WCl}_{6}-\mathrm{Ph}_{4} \mathrm{Sn}(1: 1), \mathrm{MoCl}_{5}-\mathrm{Ph}_{4} \mathrm{Sn}(1: 1)\right.$ : in toluene, $24 \mathrm{~h},[\mathrm{M}]_{0}=0.50 \mathrm{M}$, [Cat $]=20 \mathrm{mM} ; \mathrm{W}(\mathrm{CO})_{6}$ $h v$ : in $\left.\mathrm{CCl}_{4},\left[\mathrm{~W}(\mathrm{CO})_{6}\right]=10 \mathrm{mM}\right)$. 
a few minutes, showing high activity of this catalyst. Although the $\mathrm{MoCl}_{5}-\mathrm{Ph}_{4} \mathrm{Sn}$ catalyst is less active, no induction period is observed and the reaction has reached $100 \%$ conversion after $24 \mathrm{~h}$. Regarding polymerization temperature, high polymer yields are achieved at $0^{\circ} \mathrm{C}$ and above when $\mathrm{WCl}_{6}-\mathrm{Ph}_{4} \mathrm{Sn}$ is employed, whereas it is the case at $30^{\circ} \mathrm{C}$ and above with $\mathrm{MoCl}_{5}-\mathrm{Ph}_{4} \mathrm{Sn}$ and $\mathrm{W}(\mathrm{CO})_{6}-h v$ as catalysts (Figure 2). This also demonstrates the high catalytic activity of $\mathrm{WCl}_{6}-\mathrm{Ph}_{4} \mathrm{Sn}$ for $o-n$ $\mathrm{C}_{6} \mathrm{H}_{13} \mathrm{PA}$. The $\bar{M}_{w}$ of polymer was usually $c a$. $1 \times 10^{5}$ under conditions in Figure 2, showing

Table II. Polymerization of (o- $n$-alkylphenyl)acetylenes by $\mathrm{W}$ and Mo catalysts ${ }^{\mathrm{a}}$

\begin{tabular}{|c|c|c|c|c|}
\hline \multirow{2}{*}{ Catalyst } & \multirow{2}{*}{$\begin{array}{l}\text { Monomer } \\
\text { convn } / \%\end{array}$} & \multicolumn{3}{|c|}{ Polymer ${ }^{\mathbf{b}}$} \\
\hline & & Yield/\% & $\bar{M}_{w} / 10^{3 \mathrm{c}}$ & $\bar{M}_{n} / 10^{3 \mathrm{c}}$ \\
\hline \multicolumn{5}{|c|}{ alkyl: $\mathrm{H}$} \\
\hline $\mathrm{WCl}_{6}-\mathrm{Ph}_{4} \mathrm{Sn}$ & 100 & 65 & 41 & 20 \\
\hline $\mathrm{W}(\mathrm{CO})_{6}-h v^{\mathrm{d}}$ & 82 & 78 & 243 & 75 \\
\hline $\mathrm{MoCl}_{5}-\mathrm{Ph}_{4} \mathrm{Sn}$ & 35 & 14 & 25 & 6.0 \\
\hline $\mathrm{Mo}(\mathrm{CO})_{6}-h v^{\mathrm{d}}$ & 9 & 2 & 10 & 5.7 \\
\hline \multicolumn{5}{|c|}{ alkyl: Me } \\
\hline $\mathrm{WCl}_{6}-\mathrm{Ph}_{4} \mathrm{Sn}$ & 100 & 95 & 80 & 10 \\
\hline $\mathrm{W}(\mathrm{CO})_{6}-h v^{\mathrm{d}}$ & 100 & 95 & 240 & 50 \\
\hline $\mathrm{MoCl}_{5}-\mathrm{Ph}_{4} \mathrm{Sn}$ & 100 & 100 & 132 & 22 \\
\hline $\mathrm{Mo}(\mathrm{CO})_{6}-h v^{\mathrm{d}}$ & 14 & 5 & 42 & 12 \\
\hline \multicolumn{5}{|c|}{ alkyl: Et } \\
\hline $\mathrm{WCl}_{6}-\mathrm{Ph}_{4} \mathrm{Sn}$ & 100 & 100 & 30 & 11 \\
\hline $\mathrm{W}(\mathrm{CO})_{6}-h v^{\mathrm{d}}$ & 53 & 44 & 550 & 100 \\
\hline $\mathrm{MoCl}_{5}-\mathrm{Ph}_{4} \mathrm{Sn}$ & 70 & 70 & 20 & 8.3 \\
\hline $\mathrm{Mo}(\mathrm{CO})_{6}-h v^{\mathrm{d}}$ & 15 & 3 & - & - \\
\hline \multicolumn{5}{|c|}{ alkyl: $n$-Bu } \\
\hline $\mathrm{WCl}_{6}-\mathrm{Ph}_{4} \mathrm{Sn}$ & 100 & 100 & 24 & 9.5 \\
\hline $\mathrm{W}(\mathrm{CO})_{6}-h v^{\mathrm{d}}$ & 100 & 98 & 130 & 57 \\
\hline $\mathrm{MoCl}_{5}-\mathrm{Ph}_{4} \mathrm{Sn}$ & 100 & 93 & 36 & 9.0 \\
\hline $\operatorname{Mo}(\mathrm{CO})_{6}-h v^{\mathrm{d}}$ & 17 & 10 & 150 & 49 \\
\hline \multicolumn{5}{|c|}{ alkyl: $n-\mathrm{C}_{8} \mathrm{H}_{17}$} \\
\hline $\mathrm{WCl}_{6}-\mathrm{Ph}_{4} \mathrm{Sn}$ & 100 & 100 & 42 & 17 \\
\hline $\mathrm{W}(\mathrm{CO})_{6}-h v^{\mathrm{d}}$ & 96 & 84 & 120 & 28 \\
\hline $\mathrm{MoCl}_{5}-\mathrm{Ph}_{4} \mathrm{Sn}$ & 98 & 88 & 100 & 23 \\
\hline $\mathrm{Mo}(\mathrm{CO})_{6}-h v^{\mathrm{d}}$ & 16 & 11 & 79 & 20 \\
\hline \multicolumn{5}{|c|}{$\begin{array}{l}\text { a Polymerized in toluene at } 30^{\circ} \mathrm{C} \text { for } 24 \mathrm{~h} ;[\mathrm{M}]_{\mathrm{o}}= \\
0.50 \mathrm{M} \text {, [Cat }]=20 \mathrm{mM} \text {. } \\
\text { b Methanol-insoluble product. } \\
\text { c Determined by GPC. } \\
\text { d Polvmerized in } \mathrm{CCl} \text {. }\end{array}$} \\
\hline
\end{tabular}

the largest value of $\mathrm{ca} .2 \times 10^{5}$ with $\mathrm{WCl}_{6}$ $\mathrm{Ph}_{4} \mathrm{Sn}$ at $-30^{\circ} \mathrm{C}$.

Polymerizations of four homologous monomers having $o$ - $n$-alkyl groups of different lengths $\left(\mathrm{R}=\mathrm{Me}, \mathrm{Et}, n-\mathrm{Bu}\right.$, and $\left.n-\mathrm{C}_{8} \mathrm{H}_{17}\right)$ were studied by using $\mathrm{W}$ and Mo catalysts (Table II). The data of phenylacetylene are also included in Table II for the sake of comparison. These (o-n-alkylphenyl)acetylenes produced polymers in high yields with $\mathrm{W}$ and $\mathrm{Mo}$ catalysts other than $\mathrm{Mo}(\mathrm{CO})_{6}-h v$. The $\bar{M}_{w}$ values of the product polymers were in the range $1 \times 10^{4}-55 \times 10^{4}$, and tended to be higher with the $\mathrm{W}(\mathrm{CO})_{6}-h v$ catalyst. Neither of the yields and $\bar{M}_{w}$, values of the polymers was greatly affected by the length of the $o$ - $n$-alkyl group. It is, however, noted that all the (o- $n$-alkylphenyl)acetylenes polymerize in higher yields with $\mathrm{MoCl}_{5}-\mathrm{Ph}_{4} \mathrm{Sn}$ catalyst than does phenylacetylene.

\section{Polymerization of (o-iso-Propylphenyl)acety- lene \\ Results on the polymerization of $o$-iso-PrPA} are shown in Table III. All the three W catalysts in the table polymerize this monomer in over $65 \%$ yields. The polymers obtained with $\mathrm{WCl}_{6}-\mathrm{Ph}_{4} \mathrm{Sn}$ and $\mathrm{W}(\mathrm{CO})_{6}-h v$ possess $\bar{M}_{w}$ 's around $2 \times 10^{5} . \mathrm{MoCl}_{5}$ and its mixture with $\mathrm{Ph}_{4} \mathrm{Sn}$ also form poly(o-iso-PrPA)s quantitat-

Table III. Polymerization of $o$-iso-PrPA by $\mathrm{W}$ and Mo catalysts ${ }^{\mathrm{a}}$

\begin{tabular}{|c|c|c|c|c|}
\hline \multirow{2}{*}{ Catalyst } & \multirow{2}{*}{$\begin{array}{l}\text { Monomer } \\
\text { convn } / \%\end{array}$} & \multicolumn{3}{|c|}{ Polymer ${ }^{\mathrm{b}}$} \\
\hline & & Yield $/ \%$ & $\bar{M}_{w} / 10^{3 \mathrm{c}}$ & $\bar{M}_{n} / 10^{3 \mathrm{c}}$ \\
\hline $\mathrm{WCl}_{6}$ & 100 & 100 & 63 & 32 \\
\hline $\mathrm{WCl}_{6}-\mathrm{Ph}_{4} \mathrm{Sn}$ & 100 & 95 & 270 & 88 \\
\hline $\mathrm{W}(\mathrm{CO})_{6}-h v^{\mathrm{d}}$ & 66 & 65 & 220 & 81 \\
\hline $\mathrm{MoCl}_{5}$ & 100 & 100 & 59 & 27 \\
\hline $\mathrm{MoCl}_{5}-\mathrm{Ph}_{4} \mathrm{Sn}$ & 100 & 100 & 1100 & 370 \\
\hline $\mathrm{Mo}(\mathrm{CO})_{6}-h v^{\mathrm{d}}$ & 12 & 5 & 200 & 55 \\
\hline \multicolumn{5}{|c|}{$\begin{array}{l}\text { a } \text { Polymerized in toluene at } 30^{\circ} \mathrm{C} \text { for } 24 \mathrm{~h} ;[\mathrm{M}]_{\mathrm{o}}= \\
0.50 \mathrm{M},[\mathrm{Cat}]=\left[\mathrm{Ph}_{4} \mathrm{Sn}\right]=20 \mathrm{mM} \text {. } \\
\text { b Methanol-insoluble product. } \\
\text { c Determined by } \mathrm{GPC} \text {. } \\
\left.{ }^{\text {d }} \text { Polymerized in } \mathrm{CCl}_{4} ; \text { [Cat }\right]=10 \mathrm{mM} \text {. }\end{array}$} \\
\hline
\end{tabular}


ively, whereas the $\mathrm{Mo}(\mathrm{CO})_{6}-h v$ catalyst is hardly effective. Quite interestingly, the $\bar{M}_{w}$ of the polymer with $\mathrm{MoCl}_{5}-\mathrm{Ph}_{4} \mathrm{Sn}$ exceeds $1 \times 10^{6}$.

Whereas the polymerization of phenylacetylene by $\mathrm{MoCl}_{5}-\mathrm{Ph}_{4} \mathrm{Sn}$ levels off and does not reach $100 \%$ conversion, those of orthosubstituted phenylacetylenes generally reach higher conversions. This suggests that the steric effect of ortho-substituted monomers makes the termination reaction (e.g., coupling of metal carbenes) difficult.

In order to gain knowledge on the relative reactivity of ortho-substituted monomers, their copolymerizations with phenylacetylene were carried out in toluene at $30^{\circ} \mathrm{C} ;\left[\mathrm{M}_{1}\right]_{\mathrm{o}}=$ $\left[\mathrm{M}_{2}\right]_{\mathrm{o}}=0.25 \mathrm{M},\left[\mathrm{WCl}_{6}\right]=\left[\mathrm{Ph}_{4} \mathrm{Sn}\right]=20 \mathrm{mM}$. The relative reaction rates were $o-\mathrm{C}_{6} \mathrm{H}_{13} \mathrm{PA}$ : $o$-iso-PrPA: PA = 0.7:0.8:1. This indicates the ortho substituents decrease the reactivity in propagation.

\section{Polymer Properties}

The structure and properties of poly $(o-n$ $\left.\mathrm{C}_{6} \mathrm{H}_{13} \mathrm{PA}\right)$ and poly(o-iso-PrPA) were studied by using the sample obtained with the $\mathrm{WCl}_{6}-\mathrm{Ph}_{4} \mathrm{Sn}$ catalyst ( $c f$., Tables I and III).

The values of elemental analysis agreed well with the ones calculated for the polymerization products; Anal. Poly $\left(o-n-\mathrm{C}_{6} \mathrm{H}_{13} \mathrm{PA}\right)$ : Calcd for $\left(\mathrm{C}_{14} \mathrm{H}_{18}\right)_{n}: \mathrm{C}, 86.13 \%$; $\mathrm{H}, 9.41 \%$. Found: $\mathrm{C}$, $86.02 \% ; \mathrm{H}, 9.26 \%$. Poly(o-iso-PrPA): Calcd for $\left(\mathrm{C}_{11} \mathrm{H}_{12}\right)_{n}$ : $\mathrm{C}, 91.70 \% ; \mathrm{H}, 8.30 \%$. Found: C, $91.40 \% ; \mathrm{H}, 8.60 \%$.

The IR data are: $\operatorname{Poly}\left(o-n-\mathrm{C}_{6} \mathrm{H}_{13} \mathrm{PA}\right)$ : IR (KBr) 3061 (m), 3020 (m), 2957 (s), 2856 (s), $1464(\mathrm{~m}), 1377(\mathrm{~m})$, and $750(\mathrm{~s}) \mathrm{cm}^{-1}$. Poly(o-iso-PrPA): IR (KBr) 3060 (m), $3021(\mathrm{~m})$, 2959 (s), 2867 (s), 1483 (s), 1458 (m), 1443 (s), 1383 (s), 1361 (s), and $752(\mathrm{~s}) \mathrm{cm}^{-1}$. Strong absorptions at $750-752 \mathrm{~cm}^{-1}$ are characteristic of ortho-substituted benzenes. Weak bands at $1601-1607 \mathrm{~cm}^{-1}$ are assignable to $\mathrm{C}=\mathrm{C}$ stretching. The band at $3300-3310 \mathrm{~cm}^{-1}$ due to the $\equiv \mathrm{C}-\mathrm{H}$ stretching seen in the monomers has completely disappeared in the polymers.
The ${ }^{13} \mathrm{C}$ NMR spectra of poly $\left(o-n-\mathrm{C}_{6} \mathrm{H}_{13}\right.$ PA) and poly(o-iso-PrPA) show multiple peaks based on olefinic and phenyl carbons in the region $\delta 145-120$ (Figure 3). Two peaks due to the acetylenic carbons in the monomer $(\delta$ 83.6 and $80.2 \mathrm{ppm}$ for $\left.o-n-\mathrm{C}_{6} \mathrm{H}_{13} \mathrm{PA}\right)$ and $(\delta$ 82.3 and $80.7 \mathrm{ppm}$ for $o$-iso-PrPA) have disappeared in the polymers formed. These analytical and spectral data are compatible with the polymer structure composed of alternating double bonds in the main chain as shown in Figure 3.

Unlike poly(phenylacetylene) [poly(PA)], poly $\left(o-n-\mathrm{C}_{6} \mathrm{H}_{13} \mathrm{PA}\right)$, and poly (o-iso-PrPA) clearly shows absorption maxima in the visible region (Figure 4). Their wavelengths are somewhat longer than that of poly $(o-\mathrm{MePA})$. It seems a general tendency that introduction of ortho substituents onto poly(PA) generates an absorption maximum in the visible
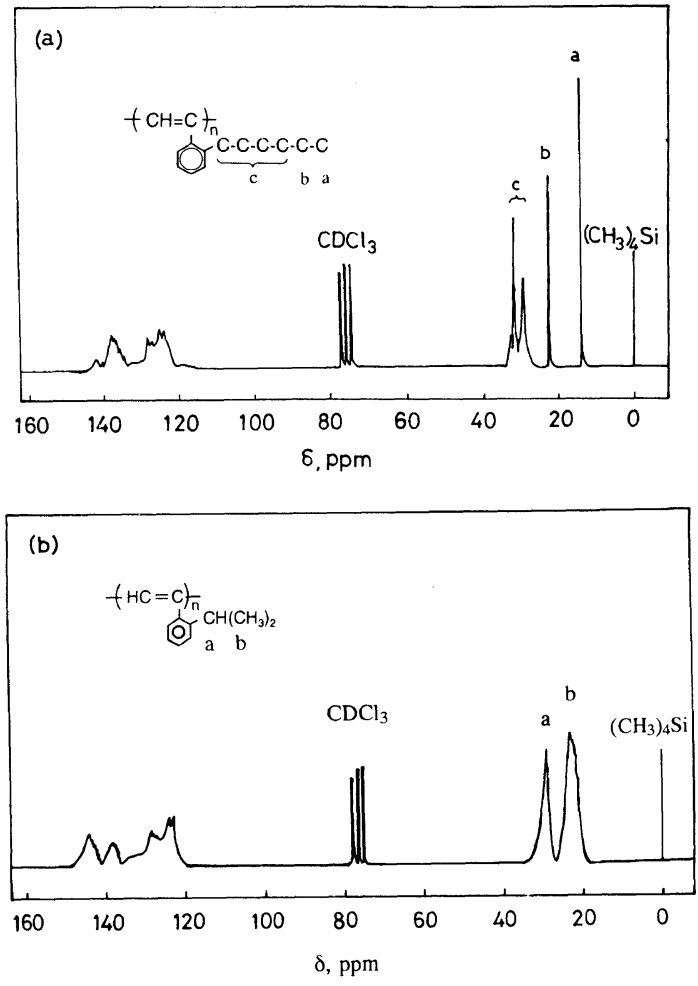

Figure 3. ${ }^{13} \mathrm{C}$ NMR spectrum of poly $\left(o-n-\mathrm{C}_{6} \mathrm{H}_{13} \mathrm{PA}\right)$ (a) and poly(o-iso-PrPA) (b) $\left(\mathrm{CDCl}_{3}\right.$ solution). 
Table IV. Properties of poly[(o-alkylphenyl)acetylenes $]^{\mathrm{a}}$

\begin{tabular}{|c|c|c|c|c|c|}
\hline & \multicolumn{5}{|c|}{ Alkyl } \\
\hline & $\mathrm{H}$ & $n-\mathrm{Bu}$ & $n-\mathrm{C}_{6} \mathrm{H}_{13}$ & $n-\mathrm{C}_{8} \mathrm{H}_{17}$ & iso-Pr \\
\hline Form & Solid & Solid & Solid & Rubbery & Solid \\
\hline$\lambda_{\max } \mathrm{b} / \mathrm{nm}$ & 225 & 487 & 483 & 457 & 465 \\
\hline$\left(\varepsilon_{\max } / \mathbf{M}^{-1} \mathrm{~cm}^{-1}\right)$ & $(6000)$ & $(5100)$ & $(4700)$ & $(4400)$ & $(4300)$ \\
\hline Softening pt $/{ }^{\circ} \mathrm{C}$ & 220 & 180 & 100 & 70 & 350 \\
\hline$T_{\mathrm{o}}^{\mathrm{c}} /{ }^{\circ} \mathrm{C}$ & 200 & 240 & 270 & 250 & 240 \\
\hline$\sigma^{\mathrm{d}} / \mathrm{S} \mathrm{cm}^{-1}$ & $4 \times 10^{-15}$ & $5 \times 10^{-13}$ & $1 \times 10^{-13}$ & - & $3 \times 10^{-15}$ \\
\hline Spin density $/ g^{-1}$ & $8 \times 10^{16}$ & $6 \times 10^{16}$ & $3 \times 10^{16}$ & $6 \times 10^{16}$ & - \\
\hline
\end{tabular}

a Polymer samples prepared with $\mathrm{WCl}_{6}-\mathrm{Ph}_{4} \mathrm{Sn}$. ${ }^{\text {b }}$ Measured in $\mathrm{CCl}_{4}$.

c Onset temperature of weight loss in TGA in air. ${ }^{d}$ Electrical conductivity.

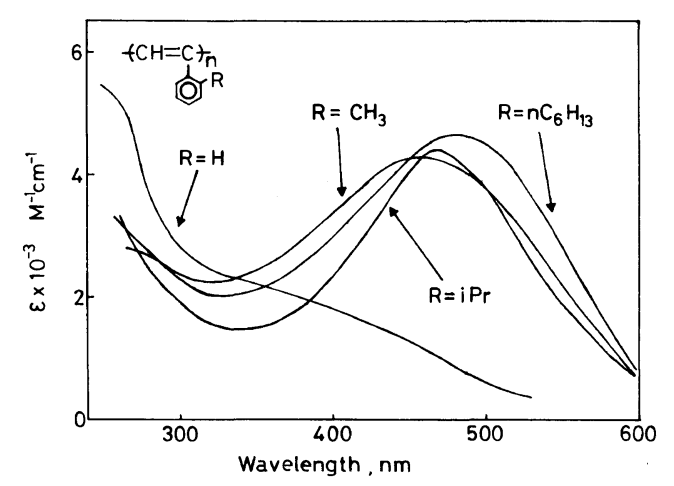

Figure 4. UV-Visible spectra of poly(phenylacetylenes) $\left(\mathrm{CCl}_{4}\right.$ solution).

region. ${ }^{6-9}$ This is probably due to that the main chain takes more conjugated conformations owing to the steric effect of ortho substituents, but the definite reason has not been reached at the moment.

While poly(PA) is a light brown solid, the polymers in the present study are dark red to dark brown substances. Their softening point progressively decreased as the $n$-alkyl group became longer (Table IV). The present polymers, including poly(o-iso-PrPA), began to lose weight at about $250^{\circ} \mathrm{C}$ in the thermogravimetric analysis (TGA) in air; these onset temperatures are higher than that of poly(PA) $\left(200^{\circ} \mathrm{C}\right)$, indicating higher thermal stability.

Table V summarizes solubility properties of the present polymers as well as of poly(PA). The present polymers completely dissolved in
Table V. Solubility of poly[(o-alkylphenyl)acetylenes] in various solvents ${ }^{\mathrm{a}}$

\begin{tabular}{|c|c|c|c|c|c|c|}
\hline \multirow{2}{*}{ Solvent } & \multicolumn{6}{|c|}{ Alkyl } \\
\hline & $\mathrm{H}$ & Et & $n-\mathrm{Bu}$ & $n-\mathrm{C}_{6} \mathrm{H}_{13}$ & $n-\mathrm{C}_{8} \mathrm{H}_{17}$ & iso- $\mathrm{Pr}$ \\
\hline $\begin{array}{l}\text { Hexane } \\
\mathrm{Et}_{2} \mathrm{O}\end{array}$ & i & ps & $\mathrm{s}$ & & S & ps \\
\hline $\begin{array}{l}\text { Toluene } \\
\left(\mathrm{CH}_{2} \mathrm{Cl}\right)_{2} \\
\mathrm{THF}\end{array}$ & $\mathrm{s}$ & $\mathrm{s}$ & $\mathrm{s}$ & & s & $\mathrm{s}$ \\
\hline $\begin{array}{l}\text { Acetophenone } \\
\text { Nitrobenzene }\end{array}$ & \} $\mathrm{s}$ & s & ps & & $\mathrm{i}$ & $\mathrm{i}$ \\
\hline $\begin{array}{l}\text { Acetone } \\
\text { Acetic acid }\end{array}$ & \} $\mathrm{i}$ & $\mathrm{i}$ & $\mathrm{i}$ & & $\mathrm{i}$ & $\mathrm{i}$ \\
\hline
\end{tabular}

a s, soluble; ps, partly soluble; i, insoluble.

aromatic hydrocarbons, halogenated hydrocarbons, and tetrahydrofuran (THF) irrespective of the kind of alkyl groups. The alkyl length affected the solubility property to some extent. Thus the polymers having long $n$-alkyl groups were soluble in aliphatic hydrocarbons, while insoluble in polar aromatic hydrocarbons. The films obtained by casting the $o$ - $n$-alkylsubstituted polymers from toluene solution were too brittle to maintain their form, probably because their molecular weights were not high enough. In contrast, a free-standing film could be fabricated by casting poly(o-isoPrPA) solution.

The present polymers were electrical insulators like poly(PA). Their unpaired-electron 
densities $\left(25^{\circ} \mathrm{C}\right)$ were in the order of $10^{16} \mathrm{spin}$ $\mathrm{g}^{-1}$.

The oxygen permeability coefficient $\left(P_{\mathrm{O}_{2}}\right)$ of poly $\left(o\right.$-iso-PrPA) at $25^{\circ} \mathrm{C}$ was 27 barrers [1 barrer $=1 \times 10^{-10} \mathrm{~cm}^{3} \quad(\mathrm{STP}) \cdot \mathrm{cm} \cdot \mathrm{cm}^{-2} \cdot \mathrm{s}^{-1}$. $\mathrm{cm} \mathrm{Hg}^{-1}$ ], and the separation factor against nitrogen $\left(P_{\mathrm{O}_{2}} / P_{\mathrm{N}_{2}}\right)$ was 2.2. The $P_{\mathrm{O}_{2}}$ value of this polymer is comparable to that of natural rubber (23 barrers). ${ }^{11}$ When compared with other ortho-substituted poly(phenylacetylenes) [poly $\left(o\right.$-MePA) 8.1 barrers, poly $\left(o-\mathrm{CF}_{3} \mathrm{PA}\right) 25$ barrers, $\operatorname{poly}\left(o-\mathrm{Me}_{3} \mathrm{SiPA}\right) 78$ barrers $\left.{ }^{12}\right]$, it turns out that bulky ortho groups tend to enhance the $P_{\mathrm{O}_{2}}$ value.

Acknowledgment. We thank Professor T. Kawamura of the Department of Applied Chemistry, Gifu University for the measurement of ESR spectra.

\section{REFERENCES}

1. T. Masuda and T. Higashimura, Adv. Polym. Sci.,
81, 121 (1986)

2. T. J. Katz and S. J. Lee, J. Am. Chem. Soc., 102, 422 (1980).

3. T. Masuda, Y. Okano, Y. Kuwane, and T. Higashimura, Polym. J., 12, 907 (1980).

4. Y. Okano, T. Masuda, and T. Higashimura, Polym. J., 14, 477 (1980).

5. T. Masuda, K. Hasegawa, and T. Higashimura, Macromolecules, 7, 728 (1974).

6. Y. Abe, T. Masuda, and T. Higashimura, J. Polym. Sci., A. Polym. Chem., 27, 4267 (1989).

7. H. Muramatsu, T. Ueda, and K. Ito, Macromolecules, 18, 1634 (1985).

8. T. Masuda, T. Hamano, T. Higashimura, T. Ueda, and H. Muramatsu, Macromolecules, 21, 281 (1988).

9. T. Masuda, T. Hamano, K. Tsuchihara, and T. Higashimura, Macromolecules, 23, 1374 (1990).

10. L. Brandsma, H. Hommes, H. D. Verkruijsse, and R. L. P. de Jong, Recl. Trav. Chim. Pays-Bas, 104, 226 (1985).

11. S. Pauly, 'Polymer Handbook," 3rd ed, J. Brandrup and E. H. Immergut, Ed., Wiley-Interscience, New York, N.Y., 1989, p VI-437.

12. T. Masuda, Y. Iguchi, B.-Z. Tang, and T. Higashimura, Polymer, 29, 2041 (1988). 